photography to spectroscopic observations. There are fe things so difficult, I think, as to make a proper spectroscopic observation, while from the little experience I have had at present I should think there is nothing more easy than to produce passable spectroscopic photographs.

That, then, was in the year 1862 . In the year 1863 we have another equally distinct advance to chronicle, but this time the work is done in France. M. Mascart-a name very well known to physicists-undertook a tremendous work, which he lias not yet completed, namely, a complete investigation of the ultra violet solar spectrum. * Instead of using a quartz prism, as Dr. Miller had done before him, M. Mascart uses a diffraction

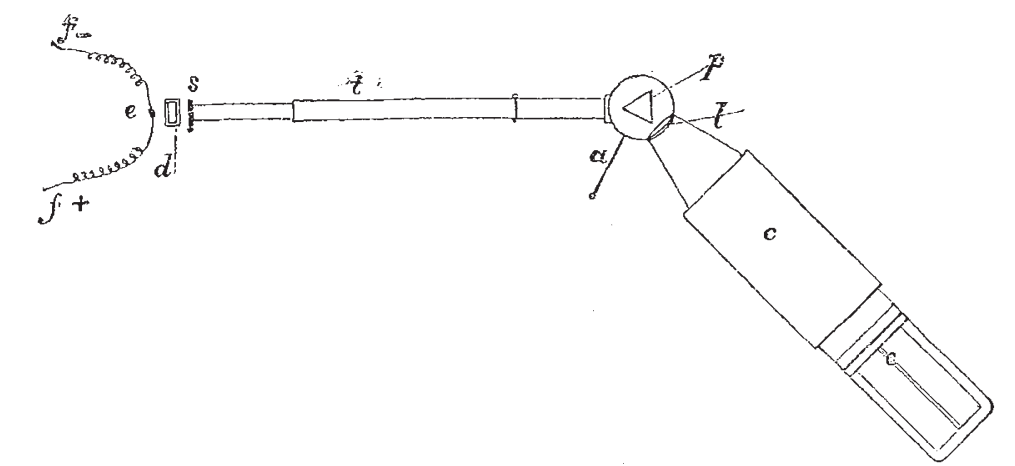

FrG. 5.-Dr. Miller's arrangements, $-s$, slit ; $h$, quartz lens ; $c$, camera $; \not p$, quartz prism ; $t$, collimator.

grating, that is to say an instrument by means of which the light is not refracted, as in the case of the prism, but diffracted by an effect of interference of fine lines ruled on glass. M. Mascart has shown it to be possible, by means of reflecting light from the first surface of the diffraction gratings, to get light diffracted without its going through the glass at all. In this way, therefore, you avoid aitogether the imperfect transparency of the glass. Prof. Mascart has gone on advancing every year, until now he has completed a photographic map, not only of the solar spectrum extending about as far as the line R., by means of photography, but he has been able to observe as far as the line called $T$. There he finds the solar spectrum ends; but in the

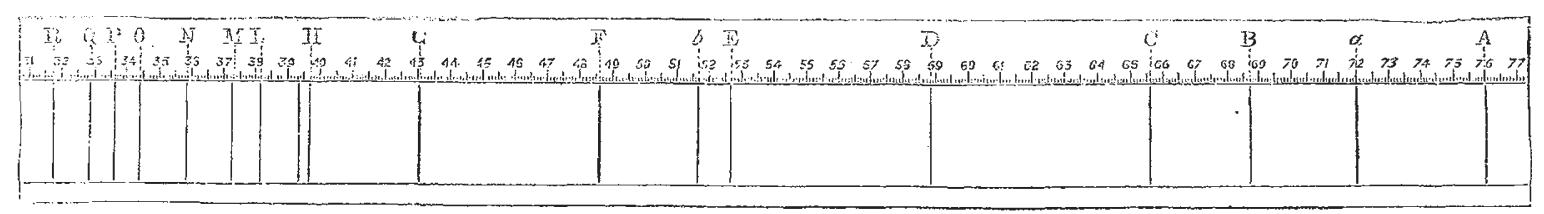

Fig. 6.-- Wave-length solar spectrum showing the lines (from $L$ to $R$ ) the positiong of which have been determined by Mascart, and showing also how short the uitra-yiolet spectrum of the sun is as compared with that of the chemical elements.

case of a gieat many vapours, such, for instance, as înat of cadmium and other metals of the same nature, he finds he can so on photograpling very much farther, and has been able to photograph almost as far as the eye can see, that is to say, to a distance, as I have already told you, five or six, or even seven times as far from the line $H$ as $H$ is from $A$. So that you see, thanks to photography, we can now photograph six times more of the spectrum than we can see of it with the eye ordinarily.

(To be continued.) J. NORMAN LOCKYER

\section{THE CENTRAL PARK OF NEW YTOKK AND MR. WATERHOUSE HAWKINS}

SOME time ago (NATURE, vol. vi. p. 70) we copied from $S$ the American Naturalist an account of the destruction "by order of Mr. Henry Hilton" of Mr. Waterhouse Hawkins' restorations of Hadrosaurzs and other extinct animals, in the Central Park of New York. We have lately received some further correspondence on this subject, from which it appears that in April last Mr. Hawkins addressed to the Board of Commissioners of the Central Park a memorial, setting forth the manner in which he had been treated, and claiming compensation for his losses. It is not very easy to understand the origin of the affair, which appears to have occurred through some change in the government of the city of New York, produced by the notorious "Ring." But it is quite evident that Mr. Hawkins has the sentiments of all the leading scientific men of the United States in his favour.

Prof. Henry, of the Smithsonian Institution, speaks of the destruction of Mr. Hawkins" models as a "disgrace to the country, which nothing can wipe out, save a renewal of the work on a more liberal scale." Prof. Newbury, and other savants, write in a similar strain. There can therefore, we suppose, be no doubt that Mr. Hawkins will ultimately receive ample compensation for the treatment which he has received from Mr. Hilton and his subordinates.

\section{EUCALYPTUS GLOBULUS IN MAURTTIUS'}

THE subject of the introduction of the Eucalypius as I a sanitary agency in fever-stricken countries has of late been so much talked about that some authoritative preliminary inquiries have been made with the view of planting Eucalypius globulus on a large scale in the Mauritius. From these inquiries, directed chiefly as to the possible success of the plant in the island, it appears that it does not thrive in any part, and still less in the warmer parts. The tree, moreover, is unsuited to resist the violent winds or hurricanes with which the Mauritius is so frequently visited. In 1865 twelve plants were planted in the Botanic Gardens at Pampelmousses, and though they were secured to strong stakes, eleven of them were destroyed in the hurricane of I 868 ; the remaining one also was blown over, but met with some support by falling into the branches of another tree, where it still remains.

Though it appears at one time thousands of young plants were planted in the lower parts of the island very few at the present time exist; there are, however, several * "Annales scientifiques de l'Ecole normale Supérieurc." Vol. for 1864 , 
specimens growing in the higher districts, at Vacoa and Moka; and a number of young trees were planted at Curepipe, of the success or failure of which, however, nothing can yet be said. Besides the frequent occurrence of devastating gales, the drought exercises an evil influence on the Eucalyptiss, which is proved from the fact of the failure from this cause alone of 200 young trees that were planted and a quantity of seed that was sown last year on the signal mountains above Port Louis. As avenue trees to be planted on each side of the streets they are sait to be the most unsuited of all the trees known in the island. The streets of Port Louis are, moreover, too narrow or too much crowded with traffic to admit of such planting.

Above and beyond all these considerations it is the opinion that no system of planting, whether of groups or avenues, in the midst of the town, or of whole forests in the outskirts, nor yet a system of sewers and surface drains, would suffice to make Port Louis a healthy town. A perfect system of subsoil clrainage throughout is considered the only possible means of a permanent improve. ment. 'The evil lies in the water, which soaks into the heavy clay subsoil, and having no means of escape becomes stagnart and putrefes.

JOHN R. JACKSON

\section{COGGTA'S COMEX}

THE following position of this comet was obiained here this evening by micrometrical comparisons with a star in the Bonn Catalogue. It should be pretty exact :- -

June 9 , at roh. $23 \mathrm{~m}$. 34s. mean time at Twickenham. R.A. . . 6h. $58 \mathrm{~m} .3 \mathrm{I} \cdot \mathrm{igs}$.

Decl. . . . $+69^{\circ} 2^{\prime} 3^{\prime \prime}$.

The comet is rather brighter than Argelander's stars of 6th magnitude, and the tail may be traced about $2^{\circ}$ from the nucleus, which still presents a very stellar appearance.

The following orbit is the best I have yet seen, and was calculated by myself from the Marseilles observation of April I7, and two made at Mr. Bishop's observatory on May 9 and June $I$; all the small corrections taken into account:-

Perihclion Passagc, July, 8.21 io Greenwich mean time.

Longitude of Perihelion ... 27\% $47^{\prime}$ 13 3 \} Mean Equinox, "Ascending Node ... 1182433$\}$ July o.

Inclination to Ecliptic $\ldots .655$ I 31

Perihelion distance ..... .0 .67437 (the earth's mean

Heliocentric motion ... ... Direct. distance $=\mathrm{I}$

The comet is steadily increasing in brirhtness, as indi. cated by theory.

Mr. Bishop's Observatory, Twickenhan, Tuesday night

\section{NOTES}

WE are informed that the whole of the large and valuable collection of Natural History specimens procured by Signor D'Albertis during his recent travels in New Guinea has been purchased by the Italian Government, and that Signor D'Albertis himself will shortly return to the same island to continue his researches, which have already proved so important.

AT the last meeting of the Royal Geographical Society, held on Monday, June I, Dr. Carpenter delivered a discourse entitled "Further Researches in Oceanic Circulation," in continuation of the communication he made to the Society on this subject four years ago. We understand that this lecture will be published in the Journal of the Society in full detail and with ample illus. trations, and that it will contain a complete discussion of the results of the Challenger Temperature-Survey of the Atlantic.
Mr. Clements R. Marikham, C.B., F.R.S., has been created a Knight Commander of the Portuguese Order of Jesus Christ.

THE Swedish Order of the Pole Star has been conferred upon Mr. Leigh Smith, the arctic voyager.

AT a Convocation of Durham University, held on June 2, certain alterations in the regulations were moved, the object o which was to prescribe the standing and exercises requisite for the academical rank of Associate in Physical Science, and of Me. chanical, Mining, and Civil Engineers, which wotld enable students who had obtained the academical rank of Associate in Physical Science to become admissible to the degree of Bachelor of Science, provided not less than two years had intervened from the time of their being made Associates, after passing an examination in not less than six of the following subjects:- $\mathrm{x}$. Mathematics (pure and applied); 2. Physics; 3. Chemistry; 4. Geology ; 5. Engineering; 6. Biology ; 7. Either Latin or Greek; 8. Either French or German; the two last of these subjects being compulsory. In title 8 , sec. $\mathbf{x}$. of the regulations, it was proposed to add the following clause:--"That students of the Durham University College of Medicine, or of the Durham University College of Physical Science at Newcastle-on-Tyne, may petition the University that terms kept by them at either of these colleges, equivalent in duration to three terms kept by stu. dents in Arts at Durham, may count towards the degree of B.A., provided that they shall have passed the first examination ap. pointed for students in Arts, which really takes place at the beginning of the second year, and that they shall not be admitted to the final examination for the degree of B. A. unless they have kept three terms at least by residence as students in Arts at Durham." The alterations were assented to.

TuERE will be an election at Merton College, Oxforl, in Oc. tober next to two postmasterships, value $80 l$. per annum, tenable for five years from election, or so long as the holder does not accept any appointment incompatible with the full pursuance of his University studies. In the examination for these postmasterships papers will be set in algebra, pure geometry, trigonometry, theory of equations, and analytical geometry of two dimensions. Candidates must not have exceeded four terms of University standing. There is no limit of age. The examination will commence on Tuesday, Oct. I3, at 9 A.M. in Merton College Hall. Candidates are required to call on the Warden on the same day between 4 and 5 P.M.

A t the election to Mathematical and Physical Science Postmaster. ships in October, at Merton College, Oxford, an election will be made to two Physical Science Postmasterships, each of the value of $80 l$. a year, and tenable for five years from election, provided that the person elected do not accept any appointment interfering with the full course of University studies. There is no limit of age, but candidates, if already members of the University, must not have exceeded six terms from matriculation. The persons elected, if not members of the University, will be required to pass the University examination for responsions within a year of election. The subjects of examination will be Chemistry and Physics. There will be a practical examination in Chemistry. Candidates will have opportunities of giving evidence of a knowledge of Biology; but it must be borne in mind, that in such cases the examiners will look for evidence of an acquaintance with the principles of Chemistry and Physics equal in extent to that which is required in the Preliminary Honour Examination in the Physical Science School. A paper will be set in Algebra and Elementary Geometry, which, cateris paribus, will be of weight in the election to the postmasterships. The examination will commence on Tuesday, Oct. I3, at 9 A.M. in Merton College Hall. Candidates are required to call on the Warden on the same day between 4 and 5 r.M. Further information may be obtained from the Tutor in Physical Science. 